\section{Medical supplies in Iran hit by sanctions}

The delivery and manufacture of vital medical supplies in Iran is being impeded by bilateral sanctions on the country's economy, imposed to force Iran to comply with international rules on nuclear programmes. This situation is causing a humanitarian disaster and contravenes the Universal Declaration of Human Rights.

Medicines are not themselves subject to sanctions, but the licensing, purchase and shipment of imported medicines have all been hit. This, combined with the potential threat of sanctions by international pharmaceutical companies and banks, has led to a shortage of specific drugs and medical facilities in Iran over the past few months, increasing drug prices by $50 \%$ and affecting more than 6 million chronically ill patients.

Experience in Iraq, Cuba, Libya and the former Yugoslavia indicates that sanctions seldom meet their political objectives. But they have caused large-scale humanitarian disasters in those countries (see, for example,

M. M. Ali and I. H. Shah Lancet

355, 1851-1857; 2000).

The Iranian authorities must take immediate action to block the effect of sanctions on the supply of medicines and of materials for hospitals and laboratories.

The international community needs to establish criteria for guaranteeing that medical products will always be exempt from sanctions.

Ali Gorji Epilepsy Research Centre, University of Münster, Münster, Germany. gorjial@uni-muenster.de

\section{Fisheries: broaden the arguments}

The split over whether catch is a useful indicator of fish abundance (D. Pauly, R. Hilborn and T. A. Branch Nature 494, 303-306;
2013) is a false dichotomy. Not because a realistic position lies somewhere in between, but because the focus is too narrow.

In the whole-ecosystem approach to fisheries management, data on all species, including by-catch species, must be considered. A broad range of information is therefore used to assess the health of fisheries worldwide, from no-data situations that rely on precautionary and riskbased approaches, to data-poor fisheries in which catch data are unreliable, as well as data-rich fisheries that are well supported by catch data and fisheryindependent surveys.

As climate change alters the distribution and abundance of different species, catch data may become less useful and new methods will be needed for assessing fish stocks. However, even the best estimates of fish numbers will not improve fisheries' health without good leadership, robust social capital, and effective conservation and stock-rebuilding policies. Alistair J. Hobday CSIRO Marine and Atmospheric Research, Hobart, Tasmania, Australia.

alistair.hobday@csiro.au Rodrigo H. Bustamante, Éva E. Plagányi CSIRO Marine and Atmospheric Research, Brisbane, Queensland, Australia.

\section{Fisheries: manage declines}

Catch data are first and foremost measures of fishery output (D. Pauly, R. Hilborn and T. A. Branch Nature 494, 303-306; 2013). A longterm decline in catch can be a warning that conditions have changed, either in the abundance and productivity of fish populations or in fishing practices. Although increases in fishing effort can sometimes temporarily restore yields, it is important to investigate the causes of declines.
When time series of commercial catch data are the only information available, there are ways to supplement them with life-history information (such as maximum body length) to expose important changes in population abundance (see C. Costello et al. Science 338, 517-520; 2012).

In areas of the world that cannot afford investigations of abundance, a reduction in fishing intensity is prudent precautionary management (see Code of Conduct for Responsible Fisheries UN Food and Agriculture Organization; 1995).

Brian R. MacKenzie, Mark R. Payne National Institute for Aquatic Resources, Technical University of Denmark, Charlottenlund, Denmark. brm@aqua.dtu.dk

\section{Australia's grant system wastes time}

We found that scientists in Australia spent more than five centuries' worth of time preparing research-grant proposals for consideration by the largest funding scheme of 2012 . Because just $20.5 \%$ of these applications were successful, the equivalent of some four centuries of effort returned no immediate benefit to researchers and wasted valuable research time. The system needs reforming and alternative funding processes should be investigated.

We surveyed a representative sample of Australian researchers and found that preparing new proposals for the National Health and Medical Research Council's project grants took an average of 38 working days; resubmitted ones took 28 days on average. Extrapolating this to all 3,727 submitted proposals gives an estimated 550 working years of researchers' time (95\% confidence interval, 513-589), equivalent to a combined annual salary cost of Aus $\$ 66$ million (US\$68 million). This exceeds the total salary bill (Aus\$61.6 million) at
Melbourne's Walter and Eliza Hall Institute, a major medicalresearch centre that produced 284 publications last year.

The grant proposals we analysed were typically $80-120$ pages long. If these were more focused, it would reduce preparation costs and could improve the quality of peer review by reducing workloads. Danielle L. Herbert, Adrian G. Barnett, Nicholas Graves Queensland University of Technology, Brisbane, Australia. n.graves@qut.edu.au

\section{Outdated taxonomy blocks conservation}

We agree with Frank Zachos and colleagues that splitting mammalian species taxonomically without scientific justification could impede their conservation (Nature 494, 35; 2013). But so does uncritically lumping them together.

Mammalogy is beleaguered by a dogmatic regard for midtwentieth-century propositions, which were seldom based on critical study and lacked phylogenetic information. Species were lumped together and incorporated into influential classification checklists to simplify regional faunas and make them more manageable for non-taxonomists.

Modern integrative approaches have shown that this tactic has hidden an incommensurable number of distinctive species from conservation efforts (W. R. Morrison et al. Biol. Conserv. 142, 3201-3206; 2009), thereby increasing the risk of extinctions.

Scepticism should be accorded to any taxonomy that is not based on comprehensive revisionary work, phylogenetic studies or, ideally, both.

Eliécer E. Gutiérrez, Kristofer M. Helgen National Museum of Natural History, Smithsonian Institution, Washington DC, USA. gutierreze@si.edu 